\title{
Teachers' curation of Australian screen content for school-based education
}

\section{Michael Dezuanni}

Queensland University of Technology, Australia

\section{Stuart Cunningham}

Queensland University of Technology, Australia

\section{Ben Goldsmith}

University of the Sunshine Coast, Australia

\section{Prue Miles}

Queensland University of Technology, Australia

\begin{abstract}
This article outlines how teachers curate Australian screen content for use in classrooms from pre-school to senior secondary school. It suggests teachers use their professional knowledge of curriculum and pedagogy to arrange screen resources, curriculum concepts and student experiences to promote learning. This complex curatorial process adds value to broadcaster and producer curation processes that aim to position cut-down clips and educational resources for classroom use. The article draws on a national research project that undertook interviews with 150 teachers in schools across Australia. The authors suggest the ongoing digital disruption of the school sector presents both opportunities and challenges for the Australian Broadcasting Corporation, The Special Broadcasting Service and the Australian Children's Television Foundation.
\end{abstract}

\section{Keywords}

Australian screen content, curatorship, education, learning, pedagogy

\section{Corresponding author:}

Michael Dezuanni, Film, Screen and Animation, Queensland University of Technology, Z6 502, Musk

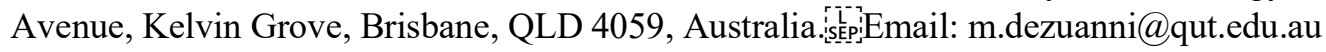

\section{Introduction}


Australia's policy settings for the development of children's television for entertainment and edu- cation suggest it remains important, in global media contexts, to provide high-quality local content for children and young people (Potter, 2015: 117). The Australian Broadcasting Corporation's ABC Splash portal, the Special Broadcasting Service's SBSLearn and the Australian Children's Television Foundation's (ACTF) educational materials, including mobile Apps, play important roles in the development of educational resources for schools. The digital disruption of schools, however, has begun to significantly alter how screen content is accessed and used by teachers and students. Until recently, there has been little insight into how teachers' classroom work transforms screen content and associated materials, such as study guides to benefit students' learning. This article deploys 'curation' as a concept to discuss how teachers use screen content to promote learn- ing. The research discussed in this article was conducted for the Australian Screen Content (ASC) in Education project, ${ }^{1}$ and reported on interviews with 150 teachers in four Australian States and one Territory. The data suggest teachers use expert curriculum and pedagogical knowledge to adapt screen content to enhance students' learning, and that they see this practice as central to their role as professional educators. Many also use screen content as a core aspect of their use of digital media technologies in the classroom.

\section{Background context}

Understanding the screen content needs and practices of Australian teachers is a complex task for policymakers, producers and distributors. The Australian school sector comprises six State and two Territory government education departments, collectively responsible for curriculum implementa- tion in over 6700 schools (Australian Bureau of Statistics (ABS), 2011). In addition, 5 metropoli- tan archdioceses and 22 dioceses manage over 1700 Catholic schools; these are complemented by approximately 1000 independent schools (ABS, 2011). Prior to 2010, each state and territory developed its own curriculum, leading to varying content in subject areas across the country. The Australian curriculum (Australian Curriculum, Assessment and Reporting Authority (ACARA), 2016a) aims to bring consistency across the sector, particularly in English, Mathematics, Science and History. There remain, however, significant differences in State and Territory implementation strategies, and this leads to variation in the use of screen content across the country. Local contexts and regional curriculum priorities allow considerable freedom for resource deployment. Therefore, while the Australian Curriculum makes it possible for Australian content producers to align screen content and teaching materials to a common national set of learning outcomes, it is by no means certain teachers will find those resources useful. 
More predictable is the availability of classroom technology in the Australian school sector. Gurr and Drysdale (2012: 405-406) argue that most Australian schools have become technologi- cally rich environments following the Australian Federal Government's 'Digital Education Revolution' (DER) programme, which saw over 1 million computers supplied to students in years 9-12 across 3000 schools and significant increases in the ratio of computers to students in years 1-8. According to the Digital Education Advisory Group (DEAG), set up by the Federal Minster for Education to make recommendations about the post-DER era, over A $\$ 2.1$ billion was invested in technology in Australian schools as part of the DER programme (DEAG, 2013). Key recom- mendations from the DEAG were that the increasing availability of mobile devices be exploited to promote 'bring your own device' (BYOD) initiatives in schools education (5), and that 'pedagogy must drive innovation in digital education' (5). Our research supports the idea that most Australian schools are now infused with digital technologies, and that most teachers access screen content via a networked computer and show it to students using a digital projection system. We also saw many students accessing digital content on their own devices or on school-provided computers (Cunningham et al., 2016).

\section{Screen content curation and PCK}

The strand of educational research informing this article is the literature exploring 'pedagogical content knowledge' which underpins the concept of teacher curation of screen content. Shulman's $(1986,1987)$ 'pedagogical content knowledge' recognizes not just what teachers teach but how they know how to teach subject matter (pedagogy). Shulman's focus is on the interdependent rela- tionship between content knowledge and pedagogical knowledge that is at the centre of successful teaching, and he suggests teachers develop expertise in managing this relationship for the benefit of students. Through deploying expertise, 'the teacher can transform understanding, performance skills, or desired attitudes or values into pedagogical representations and actions' (Shulman, 1987: 7). Shulman (1987) places emphasis on teachers' ability to decide whether teaching materials are 'fit to be taught' and argues that key to teachers' work is correcting errors of omission and commis- sion and 'the crucial process of structuring and segmenting material into forms better adapted to the teacher's understanding and ... more suitable for teaching' (p. 16). Mishra and Koehler (2006) update pedagogical content knowledge (PCK) as Technological Pedagogical Content Knowledge (TPAK), which argues Shulman's formulation should be extended to explain how technologies might be used more effectively for teaching. In this article, we argue teachers' curation practices are informed by their expert knowledge of the 
interrelations between technology, pedagogy and content.

Curation has been used in educational research to explain pedagogical practices undertaken by teachers to tailor their students' learning experience (Andrews and McDougall, 2012; Mihailidis and Cohen, 2013; Potter, 2012). Curation is a particularly useful concept for understanding digital culture practices. Hogan (2010) suggests everyday curation practices within digital culture describe how individuals select and circulate content, particularly within social networks. This contrasts with traditional media distribution and consumption where individuals have far less opportunity to tailor other audience members' experiences (Boileau, 2015). Within the education sector, textbook publishers, broadcasters and software suppliers have historically controlled access to materials to support student learning (Dewey, 1938: 18; Ito, 2009). In contrast to relative content scarcity of the past, contemporary teachers can choose from a multitude of digital resources to mediate their stu- dents' learning experiences, and this includes repurposing entertainment-oriented content for edu- cational outcomes. Bigum (2014: 4) draws on practices within the galleries, libraries, art galleries and museums (GLAM) sector to describe curation for education as a process managing disparate objects, texts, resources, concepts and people to provide individuals with new perspectives or experiences to assemble knowledge.

John Potter (2012: xv) argues curatorship involves combining digital culture elements through arranging and assembling to allow elements to be in dialogue with one another (p. 163). He sug- gests curatorship builds on authorship as 'a form of meta-authorship, which involves understand- ing the relationship between texts of all kinds: moving image, still images, print and more' (Potter, 2012: xvi). Potter's approach to curatorship may be used to describe teachers' use of digital culture elements and the curriculum brought into dialogue with each other to assemble 'the classroom' as a learning space that includes and potentially extends beyond the bricks and mortar of the school building. As an aspect of their professional practice, teachers potentially extend their personal digi- tal archive (Williams et al., 2009) to include material for classroom use. This accords with Villi's (2012) perspective that 'social' curation in digital contexts describes the 'networked distribution of

media content by adding qualitative judgment and imbuing the content with personal and social significance' (p. 615). Teacher curatorship has become more visible in digital culture as teachers combine 'found' digital resources to construct learning opportunities for their students. The suc- cess of experiences created through curating digital content into students' learning relies on the knowledge 
teachers have of the interrelations between digital technologies, content and pedagogy. Curatorship requires expert epistemic practice to mobilize the production of knowledge in mean- ingful ways, including the ability to make judgements about when and how it is appropriate to provide students with new opportunities to produce knowledge in authentic ways (Luke, 2003; Zhang, 2015).

\section{The ASC project: schools data}

The ASC project's objective was to address a lack of knowledge within industry and the education sector about the production and classroom use of screen content across the curriculum. The goal was to develop a comprehensive picture of why, how, how much and where ASC is used in educa- tion. Data were collected within both the Australian screen production and distribution industry and the school sector. The school sector data were generated through visits to 30 schools in four Australian States and the Australian Capital Territory and included individual interviews with 150 teachers. Schools were selected through convenience sampling that aimed to include a range of different school types, geographical areas and socio-economic status according to the 'Index of Community SocioEducational Advantage', used by ACARA (2016b). We visited primary and secondary schools; state, Catholic and independent schools; and schools in a geographical range from far north Queensland to Western Australia, including metropolitan and suburban Brisbane, Sydney, Melbourne, Canberra, Perth and regional Queensland and Victoria. Teachers from across the curriculum were interviewed and in most schools the teacher librarian was also interviewed. Teachers were from years 1 through 12 and were at various stages of their career, including early career teachers and teachers with over 30 years experience.

Once a school agreed to take part in the study, a school coordinator arranged teachers to take part in the interviews, so the combination of types of teachers in each school was dependent on teacher availability and willingness to participate. In the business of the school day, schedules sometimes changed at the last minute as teachers were required to undertake additional, unex- pected duties. Teachers were interviewed for approximately 20 minutes and were asked to explain their role, the kinds of screen content they typically use, their use of ASC, how they find and select screen content, what they believe students like about screen content and the parameters they use to select screen content. They were also asked to describe how they show content in a technical sense and about the kinds of educational activities they use to support screenings. They were asked about their use of support materials developed by broadcasters and their use of online resources, such as $A B C$ Splash and YouTube, and materials created by the SBS and the ACTF. Interviews were con- ducted casually and, when required, a range 
of appropriate follow-up questions were asked. The second half of the article outlines some key themes that emerged in the data, in particular learner engagement, teacher professional practice and participation in digital culture.

\section{Curating screen content to engage students in learning}

The teachers we spoke to in the ASC project are primarily motivated to use screen resources to engage students and enhance their learning. Most of our interviewees' attention was on making subject matter accessible, instructive and compelling, and this included the search for appropriate resources like online video clips at considerable time cost. A senior English teacher from a subur- ban senior secondary college explained that her personal time investment in locating video resources was considerable but worthwhile:

That's just done in the evenings. You need time to be able to research and patch things together ... and these days that aspect of my teaching, I've been teaching a long time now, is a real change in that I can now rely on the wonders of being able to have five minutes of Virginia Wolf reading her poetry [...] It adds hugely to what you are doing in the classroom. It's pretty enjoyable time, but it is a lot of time. It takes up a lot of head-space to use all these resources in this way.

For this teacher and many we interviewed, online screen content provides a searchable online archive of often highly suitable materials available to complement their classroom curriculum content. This archive is not useful, though, without research, careful selection processes and sub- stantial teacher intervention that seeks to arrange these found materials through professional judge- ment, including a highly informed understanding of students' learning needs. Teachers frequently spoke about the need to entertain students as a strategy to bring them into dialogue with subject matter. A primary schoolteacher typified responses from many teachers when she said she uses YouTube content to engage her year 1 students to learn about the literature:

It's just so quick and easy and I can use it with the little kids because often someone's made a little skit, like a cartoon about the story, which they watch and that they can really get into and I can either use that before or after the book.

Teachers' frequent examples of their use of short video clips, sometimes woven into the flow of lessons several times a week, suggest they make frequent complex professional judgements and highly informed decisions to tailor student learning experiences with a significant impact on how students interact with curriculum content and undertake learning. In terms of the specific use of Australian content, teachers' use of SBS content in upper secondary classrooms provides insight into 
the importance of engagement as a strategy to enhance learning, particularly about complex social and cultural issues.

The SBSLearn website (http://www.sbs.com.au/learn) aims to engage teachers and students in the public discussion about Australian social, political and cultural issues. This appeals to many upper secondary teachers we spoke to because it provides opportunities for teachers to involve their students in what Luke (2003) calls 'sustained conversation' and 'connectedness to the world'. A legal studies teacher in a far North Queensland secondary school explained how he used SBS' three-part documentary series Go Back to Where You Came From (2015) because he wanted to engage students in thinking about the political views of one of the show's participants and to 'raise the debate' about asylum seekers. In a similar way, a drama teacher located in a metropolitan sec- ondary school explained that she used the SBS programme First Contact (2014) to explore ques- tions of Australian identity. She said she wanted students to question the status quo and to think about Australian identity in relation to indigenous Australians, and that the SBS materials provided a good starting point because it personalized and dramatized examples of non-indigenous Australians' misunderstanding of indigenous Australians. This drama teacher also used an interac- tive documentary available on the SBSLearn website called The Boat, an award-winning interactive, graphic novel told from a refugee perspective. The associated SBSLearn materials aim to enable teachers to take students on an 'interactive journey' and include additional activity ideas, such as twitter fiction, blackout poetry and digital storytelling. She explained why she chose to use the resource in terms of the power of the resource to engage students in a visceral way:

I used The Boat as a vehicle, instead of getting them to read articles and things like that, it was really nice for them to either work in pairs or individually to read through a graphic novel in their own time and then there was also a resource that was paired with this that had really good questions [...] they found that story very engaging and talked a lot about the visual representations and the symbolism and metaphors in the work were really clear and how it really captured the emotion, in one way you can read about it but because of the soundtrack and the visuals it made it feel real.

These two teachers, and many others to whom we spoke, described their use of SBS materials as a way to bring students into the discussion about topics that are politically sensitive, at least in the Australian context. The distinctiveness of SBS content and learning materials is that they pro- vide video and interactive content that is engaging. Many of the teachers mentioned how compel- ling their students found the materials. The content also seems to resonate personally with teachers who are motivated to engage with socially and culturally challenging content. The 
materials are valuable to teachers because they support them to curate students' learning to provide a powerful and meaningful experience that connects to the curriculum outcomes they are seeking to achieve.

\section{Teachers' professional curatorial practice}

Although upper secondary teachers spoke about the SBSLearn materials in very positive ways, they also spoke passionately about their professional practice of weaving these materials into the learning objectives they set out for their students. They did not use the materials without making careful selections about which examples to use, how to use them and how to make them available to students. Indeed, most teachers in every type of school, year level and curriculum area spoke about producing their own additional educational materials to repurpose or adapt screen content and broadcaster-created 'bridging materials', such as work sheets and activities. The following perspective from an outer-suburban high school curriculum coordinator repeats a familiar theme in the interviews, regarding teachers producing their own classroom activities to complement producer-created study guides:

Yes, I often create them myself and shape it around a set of questions to hit that higher order of thinking, as the worksheets are pretty limited to what's on the screen. [...] I don't use a lot of what they have because if I pick a text to show a particular point or outcome, I'll shape it around that purpose and the worksheets don't have [those elements], particularly for higher level kids now.

This teacher's concern to address higher order thinking is typical of the work teachers identify as their role as curriculum experts with a responsibility to meet their students' specific learning needs. Many of our interviewees were quite critical of producer-created 'education' materials, such as study guides accompanying documentary films, on the basis that the learning activities were little more than 'comprehension activities'. Therefore, the teachers saw a need to undertake addi- tional work to add value to the materials. An example of this is teachers' response to $A B C$ Splash.

$A B C$ Splash is the ABC's digital education portal offering 'free, online access to video content sourced from the $\mathrm{ABC}$ Archive and third party providers, along with highly interactive, media-rich resources including games and live events, all mapped to the Australian Curriculum' (Australian Broadcasting Corporation, 2016). The site includes over 2000 video clips, many of which are cut- down excerpts of $\mathrm{ABC}$ broadcast content. Each clip is presented on a page that includes Australian Curriculum links for teachers and, sometimes, additional worksheets, information and similar 'bridging materials'. However, teachers do not always 
find these additional materials useful, or they do not use them because of the time involved in reworking materials to fit with the specific learning outcomes they are required to provide for their students. As a primary schoolteacher

librarian told us,

I direct people to $A B C$ Splash a fair bit, but I think teachers are very busy and don't get a lot of time to browse things like Splash. They are under a lot of direction and restriction with what they are expected to do as there's an awful lot of content they have to push through today. It inhibits them from actually browsing materials and curating their own material.

Despite the ABC's attempt to save teachers' time by providing them rich screen content and support materials, many of our interviewees do not use Splash at all, with lack of time for planning and adapting being the main reason. As a regional primary schoolteacher explained during a joint interview with his colleague: '[Splash] aligns well with the Australian Curriculum, but we make it align. You can't just teach what they want, you have to add your own touches to it too'. The teacher explained that a lot of discussion and thought goes into the design of students' learning: 'In plan- ning, we would talk about what we were going to be doing for the next couple of weeks, then add the resources to it. We do more of a collective (planning), rather than giving the kids the link'. His colleague explained that they aimed to teach their students to use Splash themselves as a research resource: 'We want to get the kids to think for themselves, rather than giving it to them on a platter, it's to get them thinking and find out the answer themselves'. These responses are similar to many we heard from teachers whose curation processes were not merely organizational but informed by 'pedagogical content knowledge' (Shulman, 1986), which enables teachers to bring pedagogical processes to bear on curriculum content. We spoke to very few teachers who simply use broad- caster materials without some form of additional adaptation.

\section{Screen content and digital culture}

A key theme that emerged from our interviews with teachers was that they tend to locate screen content within digital culture. While a small number of teachers spoke about screening content in 'traditional' ways, for instance, by showing a feature film uninterrupted from start to finish, the majority of teachers continuously slipped between their description of their use of digital technolo- gies and their use of screen content. This included teachers' explanations of how they provide students with opportunities to use digital devices in the classroom and their use of social media to curate screen content. From a pedagogical perspective, teachers spoke about the shift from provid- ing screen content to their students 
from the front of the room towards students accessing and making their own content on mobile devices. This was particularly the case in schools where mobile devices, such as iPads, were available. We spoke to teachers in several curriculum areas whose students are using the cameras on their mobile devices to capture content and then using apps to edit this content to communicate their understanding of ideas and concepts. For instance, one primary schoolteacher explained how his students use an app to record their workings of math- ematics problems that they then share with their peers for feedback. Another teacher's students were using iPad cameras to record recounts of historical event against a bluescreen, allowing them to layer the footage over historical photographs. A small number of our teacher interviewees were using the ACTF's My:24 app on iPads to enhance learning.

My:24 is a series of 26,12-minute documentaries about the day that changed the lives of 26 young Australian teenagers. Each of the 12-minute stories is an appropriate length to fit into a typi- cal secondary school lesson and, like the SBS content, it is uniquely placed to invite students to become part of a sustained conversation that can include the production of their own video content. The My:24 app can be downloaded onto an iOS device, and students can then use a template to

record their own ' 24 '. Beyond simply having their students make new content, some of the teach- ers said they could use the app to teach students documentary production basics. A media teacher explained how she used the My:24 app to have her students deconstruct documentaries. Another secondary media teacher explained how in future he plans to use ACTF content for student produc- tion: 'I haven't yet [used the ACTF MY:24 app] but I'm planning to for the design and production task as in-class activities, to get them to use that for design and shoot little practice excerpts for documentary'. The unique affordance of the $M y: 24$ app is that it extends students' experience of documentary beyond consumption and written response to include production of their own content to participate in the conversation about life changing moments in a rich and engaging way. In this sense, the ACTF apps provide students with an opportunity to undertake 'metaauthorship' in the manner Potter (2012: 163) argues is central to curation practices. That is, students authentically take part in digital culture as producers of moving and still images and print in addition to being screen content users, potentially leading to deeper levels of engagement with curriculum knowledge.

Teachers were also using digital technology in other ways to bring students into dialogue with screen content. For instance, a small number of mostly younger teachers told us they use social media to help build their personal and professional 
digital archive and to curate their students' learning experiences. A history teacher in a metropolitan high school explained how she combines hers and her students' personal social media use with learning:

I keep an eye on my [Facebook] news feed and that kind of thing, sometimes I subscribe to places like archeology.org or the British Museum or NatGeo and sometimes something will pop up, or BBC.

The teacher explained that she saves the emerging examples to use in class at a later date. She described this as a logical progression of her personal curation of digital content that she shares with friends and family. She also encouraged her students to use social media for learning as well as entertainment. For instance, she aims to have her students use their social media accounts to access historical information:

I got them all to follow archeology.org on Instagram, so kind of like forcing them to look at historical stuff while they are sitting there on their phones anyway, at home [...] Sometimes they come in and say, like, 'Miss, did you see this on the weekend'? They do interact with it.

These kinds of social media practices are at the vanguard of a more common theme in the data that supports the concept of teachers as curators who see themselves as mediators who create and arrange various elements, including curriculum objectives and resources to meet their students' learning needs.

\section{Conclusion}

In this article, we have argued teachers' curation practices are central to their professional practice, and that when they use screen content in the classroom they make judgements about how to best bring it into 'dialogue' with their students and other resources. It is significant to teachers' profes- sional identity that they want to meet their students' learning needs and many spoke about the pleasure of developing resources, despite the time pressures involved. At the same time, teachers clearly respond well to easily discovered and well-made materials that provide a student-centred connection to curriculum content. Teachers spoke enthusiastically about SBS resources because they like the quality of the content and the provision of rich learning materials. Although teachers

indicated they would nearly always further curate SBS content, they often seemed energized by the content itself and the suggestions made in the support materials. In contrast, it is telling that we did not speak with a single teacher who praised $A B C$ Splash for its listing of Australian Curriculum codes against its content. 
Rather, when teachers spoke positively about Splash it was about the quality of the clips on the site and that they felt they could trust resources from the national broad- caster. Finally, it is significant that teachers use screen content as an aspect of engaging students in a digital experience. Long gone are the days when screening a video in class was a special event. Digital capacity enables teachers to include screen content in the general flow of their teaching, and it allows them to have students make their own screen content. In addition, social media seems likely to play an increasing role in how teachers and students access screen content for learning. This article has aimed to provide insight into how the work of teacher curation, underpinned by expert knowledge of technology, content and pedagogy, is key to gaining insight into how screen content may be successfully deployed in the classroom. An ongoing challenge for policymakers and screen content producers and distributors is to identify ways to draw on this expertise to ensure that the highest quality screen content and educational materials are made available to children and young people.

\section{Declaration of conflicting interests}

The author(s) declared no potential conflicts of interest with respect to the research, authorship, and/or publi- cation of this article.

\section{Funding}

The author(s) disclosed receipt of the following financial support for the research, authorship, and/or publica- tion of this article: This project funded by the Australian Research Council Linkage scheme: LP130100031.

\section{Note}

1. The Australian Screen Content (ASC) in Education project was an Australian Research Council project (LP130100031) that ran from 2014 to 2016.

\section{References}

Andrews B and McDougall J (2012) Curation pedagogy for media studies: (further) towards the inexpert. Medijske studije 3(6): 152-165.

Australian Broadcasting Corporation (2016) Splash. Available at: http://splash.abc.net.au/home\#!/home (accessed 9 September 2016).

Australian Bureau of Statistics (ABS) (2011) Schools. Available at: http://www.abs.gov.au/ausstats/abs@.nsf/lookup/4221.0Main\%2BFeatures32010 (accessed 3 September 2016). 
Australian Curriculum, Assessment and Reporting Authority (ACARA) (2016a)

Australian Curriculum. Sydney, NSW, Australia. Available at:

http://www.australiancurriculum.edu.au/ (accessed 9 September 2016).

Australian Curriculum, Assessment and Reporting Authority (ACARA) (2016b) My

School. Available at: https://www.myschool.edu.au/ (accessed 30 November 2016).

Bigum C (2014) Thinking beyond massive, open and online programmed instruction. EdExEd Working paper series, Working paper no. 3. Available at:

http://chrisbigum.com/downloads/MOOPI.pdf

Boileau T (2015) Methods for teaching digital literacy skills. In: Spector JM (ed.) The SAGE Encyclopedia of Educational Technology. Available at:

http://dx.doi.org.ezp01.library.qut.edu. au/10.4135/9781483346397.n90

Cunningham S, Dezuanni M, Goldsmith B, et al. (2016) Screen Content in Australian Education: Digital Promise and Pitfalls. Brisbane, QLD, Australia: Digital Media Research Centre, Queensland University of Technology.

Dewey J (1938) Experience and Education. New York: Simon \& Schuster. íppipigital Education Advisory Group (DEAG) (2013) Beyond the Classroom: A New Digital Education for

Young Australians in the 21st Century. Available at:

https://docs.education.gov.au/system/files/doc/

other/deag_final_report.pdf (accessed 9 September 2016). (2012) Tensions and dilemmas in leading Australia's schools. School Leadership \&

Management 32(5): 403-420. social media: distinguishing performances and exhibitions

online. Bulletin of Science, Technology \& Society 30(6): 377-447.

Engineering Play: A Cultural History of Children's Software. Cambridge, MA; London: The

MIT Press.sepe A generational change, professionalization

and literate futures. Australian Journal of Language and Literacy 26(3): 5882. and media literacy educa- tion. The Journal of Interactive Media in Education 2013: 2. Available at: http://www-jime.open.ac.uk/

articles/10.5334/2013-02/ (accessed 9 September 2016). 
(2006) Technological pedagogical content knowledge: a framework for teacher

knowledge. Teachers College Record 108(6): 1017-1054.sEppitter A (2015) Creativity, Culture and Commerce: Producing Australian Children's Television with Public

Value. Bristol: Intellect.seppipotter J (2012) Digital Media and Learner Identity: The New Curatorship. New York: Palgrave Macmillan. Shulman LS (1986) Those who understand: knowledge growth in teaching. Educational Researcher 15: 4-14. Shulman LS (1987) Knowledge and teaching: foundations of the new reform. Harvard Educational Review

57: 1-22. 2 Spi: Villi M (2012) Social curation in audience communities: UDC (userdistributed content) in the networked

media ecosystem. Participations - Journal of Audience \& Reception Studies 9(2): 614632.sepi:Williams P, Leighton J and Rowland I (2009) The personal curation of digital objects. Aslib Proceedings

61(4): 340-363.sEep:Zhang S (2015) Teachers as curators: curating authentic online content for beginning and intermediate CFL

learners. Journal of Chinese Teaching and Research in the U.S 95: 128-140. 